\title{
Effects of indoor air pollution on household health: evidence from Turkey
}

\author{
Özlem IPEK ${ }^{1}$ (D) $\cdot$ Egemen IPEK $^{2}$ (D)
}

Received: 19 March 2021 / Accepted: 24 June 2021 / Published online: 13 July 2021

(C) The Author(s), under exclusive licence to Springer-Verlag GmbH Germany, part of Springer Nature 2021

\begin{abstract}
Indoor air pollution caused by the use of biomass energy in heating and cooking adversely affects the health status of household members. In Turkey, with the rapid economic growth of the last decade, biomass has been among the most consumed types of household energy for heating and cooking due to inadequate infrastructure, dependence on foreign energy, and high energy prices. This study aims to add empirical evidence to the literature on health status and indoor air pollution in Turkey caused by households' energy choices. This study analyzed these effects with random effects panel discrete ordered models using the Income Living Conditions Micro Longitudinal Data Set for the period 2014-2017. As a result of the analysis, we found that the factors of age, being female, having dependent children, and indoor air pollution have adverse effects on health status. However, education level and income level affect health status positively. The most important observation obtained from this study is that even high-income households are adversely affected by indoor air pollution due to the lack of access to clean energy resources.
\end{abstract}

Keywords Indoor air pollution · Health · Panel discrete ordered models · Turkey

\section{Introduction}

In developing countries, indoor air pollution is a public health hazard due to the use of solid biofuels such as manure, wood, crop residues, and coal for daily cooking and residential space heating. According to the World Health Organization, the use of these fuels by poor people, which number more than three billion, causes risk to households' health by creating levels of air pollution greater than those allowed by international ambient air quality standards (WHO 2018). Indoor air pollution causes increased risk of several serious conditions such as chronic respiratory disease, lung cancer, low birth weight,

Responsible Editor: Lotfi Aleya

Özlem İPEK

ozlemipek@tarsus.edu.tr

Egemen IPPEK

egemenipek@tarsus.edu.tr

1 Department of Management Information Systems, Tarsus University, 33400 Tarsus, Mersin, Turkey

2 Department of Finance \& Banking, Tarsus University, 33400 Tarsus, Mersin, Turkey pneumonia, stroke, asthma, and cataracts in adults and children (Bruce et al. 2002).

Energy choice theory is often based on the "energy stack" and the "energy ladder" models. The energy stack model assumes that households tend to choose mixed energy sources from among all alternatives and can switch energy types. On the other hand, the energy ladder model was designed as a hierarchical relationship between household income and socioeconomic status and the type of energy used for cooking and heating. The polluting effect, efficiency, and costs of fuel are generally identified by the "energy ladder" model. Fuels that are cheap, inefficient, and the heaviest polluting such as dry animal manure, fallen branches, and grasses are the bottom rung in the energy ladder. In the second rung, households use coal, kerosene, and charcoal. In the third rung, highincome households tend to use modern fuels such as electricity and LPG. Movement up the rungs of this ladder is based on the income growth of households (Barnes and Floor 1999). In developed countries, there has been a transition from biofuels to petroleum products (kerosene, LPG) and electricity. On the other hand, in developing countries, even when cleaner and more advanced fuels are available, households generally continue to use biomass (Smith 1987). Poverty is one of the main constraints in the adoption of cleaner fuels, and unfortunately, the slow growth rate in many countries indicates that biofuels 
will continue to be used by the poor. Hence, the possible dangerous effects of indoor pollution on human health caused by energy choices, which are closely related to household income and socioeconomic characteristics, should be considered.

In the literature, there have been various studies examining the health risks of indoor air pollution caused by cooking fuels on women and children, since they spend a significant amount of time near cooking stoves (Cerqueiro et al. 1990; Armstrong and Campbell 1991; Johnson and Aderele 1992; Collings et al. 1990; Shah et al. 1994; Albalak et al. 1999; Commodore et al. 2013). The first study analyzing the effect of indoor cooking smoke on children's respiratory diseases was conducted by Sofoluwe (1968). Mishra et al. (2004) investigated the relationship between the reliance on highly polluting biomass fuels such as wood, manure, or straw preferred by households and the prevalence of acute respiratory infections in children using the crosssectional logistic regression method. The results show that children living in households using biomass fuels are more than twice as likely to be exposed to acute respiratory diseases. Agrawal and Yamamoto (2015) analyzed the effect of cooking smoke produced by biomass and solid fuel combustion on asthma reported among adult men and women in India using multivariate logistic regression on cross-sectional data. The results show that adult women living in households using biomass and solid fuels are more likely to have asthma. Again, Mishra (2003) analyzed the effect of cooking smoke on asthma using logistic regression for elderly adults. The study results suggest that exposure to food smoke is strongly associated with asthma regardless of other demographic factors such as age, education, and standard of living. Duflo et al. (2008), Bruce et al. (2000), De Francisco et al. (1993), and Khalequzzaman et al. (2007) are other studies investigating the effect of cooking smoke on health.

Similarly, Boy et al. (2002) examined the relationship between exposure to indoor air pollution caused by heating energy choice during pregnancy and low birth weight in rural Guatemala. Lakshmi et al. (2013) investigated the relationship between indoor pollution and adverse pregnancy outcomes such as miscarriage and postnatal infant mortality using the Poisson regression. Both studies found a strong correlation between stillbirths and low birth weight and indoor pollution. Morris et al. (1990) analyzed the effects of fuels used in heating on respiratory tract diseases using a multiple logistic regression based on self-reported health data. They concluded that households living in homes heated with biomass have a high risk of respiratory disease. In addition, there are also various studies investigating the relationship between health status and indoor air pollution (Ezzati and Kammen 2001, 2002; Demjén et al. 2000; Bruce et al. 2002; Smith et al. 2000).

Previous studies have also shown that there are strong associations between indoor air pollution and acute lower respiratory tract infections in young children, chronic obstructive pulmonary disease, and lung cancer in adult women (Fullerton et al. 2008; Salvi and Barnes 2010; Dionisio et al. 2008; Ezzati 2005; Kim et al. 2011; Bruce et al. 2000, 2004). Moreover, studies have determined the nexus between exposure to coal and biomass smoke and lung cancer in men and women (Subramanian and Govindan 2007; Shrestha and Shrestha 2005), asthma in school-age children (Smith et al. 2000; Mishra 2003; Schei et al. 2002) Kovesi et al. 2006), and cataracts and tuberculosis in adults (Ezzati and Kammen 2001, 2002; Mishra et al. 1999; Saha et al. 2005).

Although there are various studies investigating the health effects of indoor pollution in less developed countries, there are relatively few studies on developing countries in the literature (Qiu et al. 2019; Kim et al. 2011; Pérez-Padilla et al. 2010). Despite rapid economic growth in Turkey since the early 2000s, biomass fuels such as manure, straw, and wood are still preferred by the poorest and most vulnerable households for cooking and heating due to reasons such as inequalities in income distribution, high energy prices, and lack of infrastructure.

In general, the term air pollution is usually only considered in the context of outdoor air pollution However, the indoor microenvironment has its own pollutants and pollution levels indoors are generally higher than those outdoors (Hoskins 2003). In addition, cooking stoves and heaters are usually used for several hours each day and at times when people are present indoors, their exposure effectiveness is high; that is, the percentage of their emissions that reaches people's breathing zones is much higher than for outdoor sources (Agrawal 2012). Over most of the world cooking and heating add a considerable contribution to the overall air pollution load in a dwelling (Smith 1993). Because of this, indoor spaces are important micro-environments when considering the impact of air pollution on health (Dutt et al. 1996; Pearce 1996).

Presently, the whole world continues to be affected by the rapid spread of the COVID-19 epidemic, which has spread globally since the beginning of 2020. In particular, during the COVID-19 pandemic, quarantine implications and lockdowns have also increased the time spent indoors. Therefore, determining the effects of indoor air pollution on human health has again become an important issue for researchers and politicians. Although indoor air pollution is generally caused by wet or damp walls, cigarette smoke, house dust, and the properties of the dwellings themselves, energy fuel choice in dwellings is the most critical factor that causes indoor pollution. Particularly in developing countries like Turkey, even though income, economic growth, or socioeconomic factors trigger the transition from dirty fuels to clean fuels, many households rely on biomass fuels for cooking and heating. Therefore, the primary motivation for this is study is to provide important evidence for policies targeting a reduction in indoor air pollution and its effect on health. The study investigated the impacts of indoor air pollution on health 
status caused by energy choice in Turkey by applying the random effects panel discrete ordered models on the Income and Living Conditions Research Micro Longitudinal Data Set (2014-2017). To the best of our knowledge, this study is the first to analyze the potential health effects of indoor air pollution based on energy choice in Turkey and is expected to fill a gap in the relevant literature by providing empirical results thereof.

The remainder of the paper is organized as follows: Section 2 provides the data sets used for the empirical analysis, Section 3 details the empirical strategy, Section 4 presents the econometric results, and Section 5 presents the discussion of the results.

\section{Data and methodology}

\section{Data}

In this study, the Income and Living Conditions Micro Longitudinal Data Set (ILC) was used in determining the nexus between household health status and indoor air pollution in Turkey. The ILC contains 4-waves panel microdata including overlapping records in the years of 2017-2016-2015-2014. The design of the ILC is a two-stage stratified cluster sampling. Household is described as the final sampling unit in the survey. It is possible to produce country-wide estimates from the annual panel research results. In the study, observations without available data for the basic variables, and observations for household members except the heads of households were excluded from the data set. The data set is a 4-year balanced panel, and it includes a total of 4881 households and 19,524 observations.

In the analysis, the health status of the head of the household was used as the dependent variable. Health status was measured as a 5 -Likert scale (from $1=$ very bad to $5=$ very good) based on self-reported health status. In the survey, the household answered the question "How is your health?" Since self-reported health status is an ordered categorical variable, we preferred random effects panel discrete ordered models in the study. Indoor air pollution refers to chemical, biological, and physical contamination of indoor air. It may result in adverse health effects (OECD 2021). However, indoor air pollution is not directly measurable and the ILC data set includes only the primary energy source used by households. Therefore, the energy choices of households have been analyzed under the assumption of the energy ladder hypothesis. According to this hypothesis, pollution decreases as primitive fuels are exchanged for modern fuels. For this reason, the energy type preferred by households is regarded as indoor air pollution in the study.

Besides indoor pollution, frequently used demographic and economic variables that are related to the individuals' health status in the literature are also included in the model. Educational status, gender, age, marital status, and dependent child dummy variables were taken as demographic factors. The household economic status variables of homeownership, log income, and SoL index were also added to the model as exogenous variables. Table 1 provides definitions and summary statistics of the variables used in the study.

It is widely accepted that there is a strong relationship between individuals' health and housing conditions. Exposure to indoor air pollution is tightly linked with household access to, and choice of, energy source (Ezzati 2005). Therefore, using the principal components analysis, we created the standard of living index using physical properties of homes associated with health, such as bathrooms, toilets, kitchens, water systems, hot water systems, and economic assets such as telephones, internet services, TVs, and computers. Subsequently, we divided the SoL index into four subgroups of low, medium, high, and very high, and later the households were clustered.

Although there are external environmental factors such as air temperature, humidity, air quality, precipitation, and land surface wetness can all influence the indoor environment (Institute of Medicine 2011:18). These factors are generally taken into account through region or urban/rural variables in the literature (Albalak et al. 2001; Breysse et al. 2010; Dionisio et al. 2008; Gao et al. 2009). However, we could not consider external environmental factors in this study neither directly nor indirectly due to lack of data availability.

The energy ladder hypothesis assumes that households follow a certain energy path depending on household income levels or living standards. Graph 1 clearly shows that as one ascends the steps of energy type used as a basis in the household, health status improves. Also, it presents a positive relationship between SoL and individuals' health status. It also shows that there is a decrease in the health status of households using electricity as their primary energy source. This is due to the fact that even when households have sufficient income levels, electrical energy cannot be used efficiently for heating due to inadequate infrastructure. Moreover, the positive impact of electrical energy on health due to low emissions is significantly reduced because of insufficient heating.

\section{Methodology}

The health status of the head of household was used as a dependent variable in the study. Because this variable is ordered and categorical, we preferred ordered discrete choice models considering the unobserved individual heterogeneity. Random effect discrete ordered models fit via maximum likelihood the random effects model.

$\operatorname{Pr}\left(y_{i t}>j \mid \boldsymbol{J}, x_{i t}, v_{i}\right)=\Omega\left(x_{i t} \beta+v_{i}-J_{j}\right)$ 
Table 1 Description of variables

\begin{tabular}{|c|c|c|c|c|c|c|}
\hline & Variable & Definition & Mean & S.D. & Min & Max \\
\hline \multirow[t]{5}{*}{ Dependent variable } & \multirow[t]{5}{*}{ Self-reported health } & (1) Very bad & 0.01 & 0.10 & 0 & 1 \\
\hline & & (2) $\mathrm{Bad}$ & 0.11 & 0.32 & 0 & 1 \\
\hline & & (3) Fair & 0.26 & 0.44 & 0 & 1 \\
\hline & & (4) Good & 0.55 & 0.50 & 0 & 1 \\
\hline & & (5) Very good & 0.05 & 0.23 & 0 & 1 \\
\hline \multirow{5}{*}{$\begin{array}{l}\text { Indoor air pollution (caused by type of } \\
\text { main energy sources of households) }\end{array}$} & Level of indoor & Very unhealthy & 0.02 & 0.15 & 0 & 1 \\
\hline & \multirow[t]{4}{*}{ Air pollution } & Unhealthy & 0.16 & 0.37 & 0 & 1 \\
\hline & & Moderate & 0.33 & 0.47 & 0 & 1 \\
\hline & & Good & 0.41 & 0.49 & 0 & 1 \\
\hline & & Very good & 0.05 & 0.22 & 0 & 1 \\
\hline \multirow{10}{*}{$\begin{array}{l}\text { Demographics characteristics of head } \\
\text { of household }\end{array}$} & Gender & If female $=1$ otherwise $=0$ & 0.18 & 0.39 & 0 & 1 \\
\hline & Marital status & If married $=1$ otherwise $=0$ & 0.80 & 0.40 & 0 & 1 \\
\hline & Age & Age is numerically measured. & 50.54 & 15.11 & 18 & 95 \\
\hline & Dependent child & If there is a dependent child $=1$ & 0.57 & 0.50 & 0 & 1 \\
\hline & \multirow[t]{6}{*}{ Education } & No literacy & 0.07 & 0.26 & 0 & 1 \\
\hline & & Literate & 0.06 & 0.23 & 0 & 1 \\
\hline & & Primary school & 0.41 & 0.49 & 0 & 1 \\
\hline & & Secondary school & 0.12 & 0.32 & 0 & 1 \\
\hline & & High school & 0.18 & 0.38 & 0 & 1 \\
\hline & & Higher education & 0.17 & 0.37 & 0 & 1 \\
\hline \multirow[t]{6}{*}{ Economic characteristics } & Home ownership & Homeownership $=1$ otherwise $=0$ & 0.66 & 0.47 & 0 & 1 \\
\hline & Log income & Log of household income & 7.96 & 0.55 & 0 & 1 \\
\hline & \multirow[t]{4}{*}{ Standard of living } & (1) Low & 0.24 & 0.43 & 0 & 1 \\
\hline & & (2) Medium & 0.08 & 0.27 & 0 & 1 \\
\hline & & (3) High & 0.20 & 0.40 & 0 & 1 \\
\hline & & (4) Very high & 0.46 & 0.49 & 0 & 1 \\
\hline
\end{tabular}

for $i=1, \ldots, n$ panels, where $t=1, \ldots, n_{i}, y$ is the observed ordinal responses, $\boldsymbol{J}$ is a set of cut points $j_{1}, j_{2}, \ldots, j_{J-1}$, where $J$ is the number of possible outcomes, and $v_{i}$ is independent and identically distributed $N\left(0, \sigma_{v}^{2}\right)$. If $\Omega($.$) is the logistic cu-$ mulative distribution function, it is a random effect ordered logit model. On the other hand, if $\Omega($.$) is the standard normal$ cumulative distribution function, it is a random effect ordered probit model.
From the above, we can derive the probability of observing outcome $j$ for response $y_{i t}$ as

$$
\begin{gathered}
p_{i t j} \equiv \operatorname{Pr}\left(y_{i t}=j \mid \boldsymbol{J}, x_{i t}, v_{i}\right)=\operatorname{Pr}\left(j_{J-1}<X_{i t} \beta+v_{i}+\varepsilon_{i t} \leq J_{j}\right) \\
=\operatorname{Pr}\left(j_{J-1}-X_{i t} \beta-v_{i}<\varepsilon_{i t} \leq J_{j}-X_{i t} \beta-v_{i}\right) \\
=\Omega\left(J_{j}-X_{i t} \beta-v_{i}\right)-\Omega\left(j_{J-1}-X_{i t} \beta-v_{i}\right)
\end{gathered}
$$

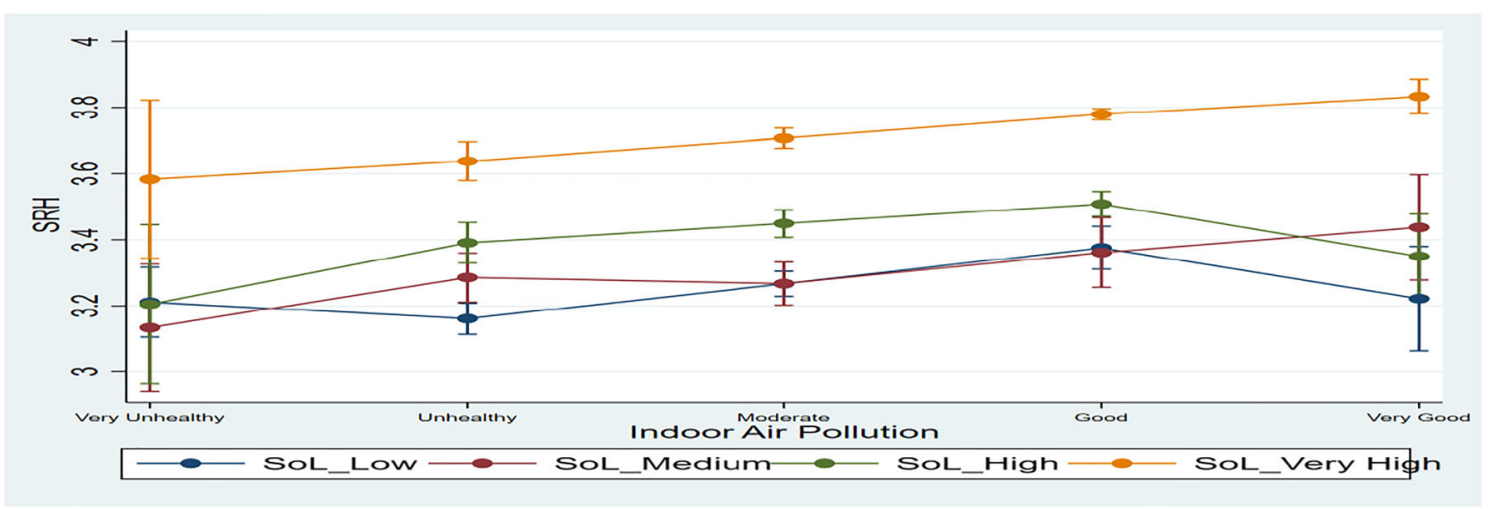

Graph 1 Estimated means of SRH by level of indoor air pollution and SoL with 95\% CIs 
where $j_{0}$ is taken as $-\infty$, and $j_{j}$ is taken as $+\infty$. Here, $X_{i t}$ does not contain a constant term, because its effect is absorbed into the cut points.

We may also express this model in terms of a latent linear response, where observed ordinal responses $y_{i t}$ are generated from the latent continuous responses, such that:

$$
\begin{aligned}
& S R H_{i t}^{*}=X_{i t} \beta+v_{i}+\varepsilon_{i t} \\
& S R H_{i t}=\left\{\begin{array}{ccc}
1 & \text { if } & S R H_{i t}^{*} \leq j_{1} \\
2 & \text { if } & j_{1}<S R H_{i t}^{*} \leq j_{2} \\
& & \vdots \\
J & \text { if } & j_{j-1}<S R H_{i t}^{*}
\end{array}\right.
\end{aligned}
$$

where $S R H_{i t}^{*}$ indicates the health status of the $i$ th household head at time $t . J$ is the number of possible outcomes, and $j_{i}$ is a set of cut points. $X_{i t}$ is a matrix of explanatory variables, representing indoor pollution caused by household energy type (dried dung, firewood, charcoal, natural gas, and electricity) and socioeconomic variables (such as age, gender, education, income, and SoL) for the household. $\beta$ is a predicting parameter vector of the explanatory variables. Depending on the distribution property of the error term $\varepsilon_{i t}$, the random effect discrete ordered model is separated into either random effect ordered logit or random effect ordered probit models. If the error term $\varepsilon_{i t}$ is distributed as standard normal with mean zero and variance one, it is called a random effect probit model. However, if the error term $\varepsilon_{i t}$ is distributed as logistic with mean zero and variance $\pi^{2} / 3$, it is called a random effect ordered logit model. Except for the assumption of the distribution of error terms, there is no significant difference between the two models. For this reason, in the study, the model results are estimated by both methods and the findings are interpreted based on the goodness of fit model results.

\section{Empirical results}

In analyses, if there is a serial correlation in the error term or the panel data do not have an identical distribution, clustering over the panel variable allows us to obtain consistent estimators (Wooldridge 2002; Baltagi 2001). For this reason, we applied the Wooldridge autocorrelation test for serial correlation. The null hypothesis, which claims there is no serial correlation, was rejected. Therefore, we obtained robust clustered standard errors by Huber/White/sandwich variancecovariance matrix estimators (Wooldridge 2020).

Clustering on the panel variable produces a consistent VCE estimator when the disturbances are not identically distributed over the panels or existence serial correlation in the error term. The cluster robust VCE estimator requires the existence of many clusters and for the disturbances to be uncorrelated across them. The panel variable must be nested within the cluster variable because of the within-panel correlation, which is generally induced by the random effects transformation when heteroskedasticity or within-panel serial correlation in the idiosyncratic errors exists.

Equation 2 shows that parameters $\beta$ do not have a subscript $j$. It implies that the estimated coefficients in discrete ordered models are assumed to be the same regardless of the category of the output variable. This assumption is called the parallel line assumption or the proportionalodds assumption. In our model, log income ( $P$-value $0.55)$, the homeowner ( $P$-value 0.23$)$, and marital status $(P$-value 0.11$)$ violate the parallel line assumption at the 0.10 level. Although there is much evidence that the assumptions of the ordered models are frequently violated (Long and Freese 2014), we applied the parallel lines restriction for these three variables. The AIC and BIC statistics can be used to evaluate the trade-off between the better fit of the restricted model and the loss of parsimony from having a $J-1$ coefficient for each independent variable instead of just one (Long and Freese 2014). The smaller values of both the AIC and BIC statistics were obtained for the unrestricted model in which the parallel regression assumption is relaxed compared with the restricted model. ${ }^{1}$

Table 2 contains both random effects ordered logit and random effects ordered probit model results. The estimation results of both models are parallel to each other. However, a random effect ordered logit model fits the data set better when the AIC, BIC, and Log pseudo-likelihood values are compared. Moreover, Mc Fadden, Cox-Snell, and Cragg-Uhler pseudo $R^{2}$ values are calculated for the model goodness of fit. All pseudo $R^{2}$ values show that the random effect logit model has higher goodness of fit than the random effect probit model. The panel-level variance component of the random effect (sigma2 u) is both large and significant. This result supports that our empirical model captures unobserved heterogeneity between the households. Cut points represent the values of $j_{j}$ in Eq. 2 and are not expected to be statistically equal. If the ordered cut points are identical to each other, the relevant cut point must be eliminated. The null hypothesis is tested by the Wald test and the null hypothesis is strongly rejected. It implies that cut points are not statistically equal.

Since both model estimation coefficients are not practical for interpretation directly, marginal effects are estimated to better understand the analysis results. Marginal effects are estimated when other estimators are assumed constant at a certain level (usually for mean or median values), and they represent the relationship between their predicted probabilities. In other words, marginal effects measure how the probability of the output changes when the value of the estimator changes by one unit. Marginal effects of the REOLOGIT model are given in Table 3 .

\footnotetext{
$\overline{{ }^{1} \text { AIC and BIC }}$ values for restricted model are 35,857.17 and 35,809.85, respectively.
} 
Table 2 Estimation results of REOPROBIT and REOLOGIT models

\begin{tabular}{|c|c|c|c|c|c|}
\hline & \multirow[t]{2}{*}{ Variables } & \multicolumn{2}{|l|}{ REOPROBIT } & \multicolumn{2}{|l|}{ REOLOGIT } \\
\hline & & Coefficient & $\begin{array}{l}\text { Cluster robust } \\
\text { Std. Err. }\end{array}$ & Coefficient & $\begin{array}{l}\text { Cluster robust } \\
\text { Std. Err. }\end{array}$ \\
\hline \multirow[t]{5}{*}{ Indoor air pollution } & Very unhealthy & Base category & & & \\
\hline & Unhealthy & $0.2432 * *$ & 0.0989 & $0.4281 * *$ & 0.1813 \\
\hline & Moderate & $0.2196^{* *}$ & 0.0966 & $0.3877 * *$ & 0.1773 \\
\hline & Good & $0.2828 * * *$ & 0.0988 & $0.5163 * * *$ & 0.1813 \\
\hline & Very good & $0.3170 * * *$ & 0.1133 & $0.5679 * * *$ & 0.2082 \\
\hline \multirow{10}{*}{$\begin{array}{l}\text { Demographics characteristics } \\
\text { of head of household }\end{array}$} & Female & $-0.3656 * * *$ & 0.0475 & $-0.6727 * * *$ & 0.0869 \\
\hline & Married & 0.0004 & 0.0433 & -0.0210 & 0.0788 \\
\hline & Age & $-0.0460 * * *$ & 0.0014 & $-0.0842 * * *$ & 0.0025 \\
\hline & Dependent child: yes & $-0.0814 * *$ & 0.0331 & $-0.1355^{* *}$ & 0.0604 \\
\hline & No literacy & Base category & & & \\
\hline & Literate & $0.2886^{* * *}$ & 0.0804 & $0.5317 * * *$ & 0.1465 \\
\hline & Primary school & $0.5940 * * *$ & 0.0656 & $1.0647 * * *$ & 0.1204 \\
\hline & Secondary school & $0.6565 * * *$ & 0.0803 & $1.1826 * * *$ & 0.1478 \\
\hline & High school & $0.7923 * * *$ & 0.0776 & $1.4306 * * *$ & 0.1427 \\
\hline & Higher education & $1.0630 * * *$ & 0.0805 & $1.9293 * * *$ & 0.1486 \\
\hline \multirow[t]{6}{*}{ Economic characteristics } & Homeowner: yes & $0.1257 * * *$ & 0.0322 & $0.2278 * * *$ & 0.0592 \\
\hline & Log income & 0.0409 & 0.0274 & 0.0662 & 0.0500 \\
\hline & SoL_Low & Base category & & & \\
\hline & SoL_Medium & $0.0956^{* *}$ & 0.0474 & $0.1813 * *$ & 0.0855 \\
\hline & SoL_High & $0.1533 * * *$ & 0.0409 & $0.2728 * * *$ & 0.0740 \\
\hline & SoL_Very High & $0.2729 * * *$ & 0.0408 & $0.4875 * * *$ & 0.0745 \\
\hline \multirow[t]{5}{*}{ Cut points of outcomes } & /cut1 & $-4.7132 * * *$ & 0.2585 & $-8.8271 * * *$ & 0.4734 \\
\hline & /cut2 & $-2.8533 * * *$ & 0.2534 & $-5.2832 * * *$ & 0.4631 \\
\hline & /cut3 & $-1.3550 * * *$ & 0.2514 & $-2.5791 * * *$ & 0.4596 \\
\hline & /cut4 & $1.4582 * * *$ & 0.2492 & $2.5570 * * *$ & 0.4554 \\
\hline & /sigma2_u & $0.7174 * * *$ & 0.0306 & $2.4447 * * *$ & 0.1034 \\
\hline \multirow[t]{4}{*}{ Model diagnostics } & Number of Obs & 19,524 & & 19,524 & \\
\hline & Number of groups & 4881 & & 4881 & \\
\hline & Wald chi ${ }^{2}(18)$ & 3130.24 & & 3078.06 & \\
\hline & Wooldridge $F(1,4880)$ & $36.394 * * *$ & & $36.394 * * *$ & \\
\hline \multirow[t]{7}{*}{ Goodness of fits } & Log pseudolikelihood & $-17,842.454$ & & $-17,756.499$ & \\
\hline & AIC & $35,730.91$ & & $35,559.00$ & \\
\hline & $\mathrm{BIC}$ & $35,912.13$ & & $35,740.22$ & \\
\hline & Pseudo $R^{2}$ & 0.034 & & 0.039 & \\
\hline & Mc Fadden $R^{2}$ & 0.034 & & 0.039 & \\
\hline & Cox-Snell $R^{2}$ & 0.064 & & 0.072 & \\
\hline & Cragg-Uhler $R^{2}$ & 0.075 & & 0.084 & \\
\hline
\end{tabular}

$* * * P<0.01, * * P<0.05, * P<0.10$

Table 3 shows the effect of the factor affecting health status compared to the reference group based on each health level when the other variables are constant at their average levels. As the level of indoor air pollution improves in households with very bad, poor, and moderate health levels, the probability of being at their current health level decreases. On the other hand, in households at the good and very good health levels, as the level of indoor pollution improves, the probability of being at these health levels increases significantly. Households with good health levels increase their chances of achieving the unhealthy, moderate, good, and very good indoor air pollution levels by $6 \%, 5.5 \%, 7 \%$, and $7.8 \%$, respectively. 
Table 3 Marginal effects at the sample mean

\begin{tabular}{|c|c|c|c|c|c|}
\hline Variable & $\begin{array}{l}\text { SRH=1 } \\
\text { Very bad }\end{array}$ & $\begin{array}{l}\text { SRH=2 } \\
\text { Bad }\end{array}$ & $\begin{array}{l}\text { SRH=3 } \\
\text { Fair }\end{array}$ & $\begin{array}{l}\text { SRH=4 } \\
\text { Good }\end{array}$ & $\begin{array}{l}\text { SRH=5 } \\
\text { Very good }\end{array}$ \\
\hline Unhealthy & $-0.0016 * *$ & $-0.0282 * *$ & $-0.0426^{* *}$ & $0.0610 * *$ & $0.0113 * * *$ \\
\hline Moderate & $-0.0015^{*}$ & $-0.0257 * *$ & $-0.0383 * *$ & $0.0554 * *$ & $0.0101 * * *$ \\
\hline Good & $-0.0018 * *$ & $-0.0321 * *$ & $-0.0499 * * *$ & $0.0702 * * *$ & $0.0136^{* * *}$ \\
\hline Very good & $-0.0020 * *$ & $-0.0354 * * *$ & $-0.0563 * * *$ & $0.0780 * * *$ & $0.0156^{* * *}$ \\
\hline Female & $0.0024 * * *$ & $0.0418 * * *$ & $0.0642 * * *$ & $-0.0909 * * *$ & $-0.0175 * * *$ \\
\hline Age & $0.0002 * * *$ & $0.0047 * * *$ & $0.0085^{* * *}$ & $-0.0108 * * *$ & $-0.0026 * * *$ \\
\hline Dependent child & $0.0004 * *$ & $0.0082 * *$ & $0.0150 * *$ & $-0.0190 * *$ & $-0.0046^{* *}$ \\
\hline Literate & $-0.0041 * * *$ & $-0.0461 * * *$ & $-0.0371 * * *$ & $0.0800 * * *$ & $0.0073 * * *$ \\
\hline Primary school & $-0.0066 * * *$ & $-0.0845 * * *$ & $-0.0881 * * *$ & $0.1594 * * *$ & $0.0198 * * *$ \\
\hline Secondary school & $-0.0069 * * *$ & $-0.0911 * * *$ & $-0.0995 * * *$ & $0.1743 * * *$ & $0.0232 * * *$ \\
\hline High school & $-0.0075 * * *$ & $-0.1039 * * *$ & $-0.1249 * * *$ & $0.2048 * * *$ & $0.0315 * * *$ \\
\hline Higher education & $-0.0082 * * *$ & $-0.1242 * * *$ & $-0.1760 * * *$ & $0.2552 * * *$ & $0.0532 * * *$ \\
\hline Homeowner & $-0.0007 * * *$ & $-0.0131 * * *$ & $-0.0230 * * *$ & $0.0299 * * *$ & $0.0068 * * *$ \\
\hline SoL_Medium & $-0.0006^{* *}$ & $-0.0110^{* *}$ & $-0.0169^{* *}$ & $0.0239 * *$ & $0.0045^{*}$ \\
\hline Sol_High & $-0.0009 * * *$ & $-0.0171 * * *$ & $-0.0273 * * *$ & $0.0378 * * *$ & $0.0075 * * *$ \\
\hline SoL_Very high & $-0.0015 * * *$ & $-0.0287 * * *$ & $-0.0496^{* * *}$ & $0.0650 * * *$ & $0.0147 * * *$ \\
\hline
\end{tabular}

$* * * P<0.01, * * P<0.05, * P<0.10$

Note: Only the statistically significant effects are listed. Marginal effects of the REOPROBIT are available upon request
Moreover, the factors of age, having dependent children, and being a woman increase the probability of being at fair and lower health status and decrease the possibility of having good or very good health status levels. These results are consistent with existing literature and the realities of the country, since women are responsible for cooking and spend long periods at home due to their gender role in Turkey. Furthermore, income level, education level, and homeownership decrease the probability of having fair or below health status and increase the possibility of having good or very good health status levels.

\section{Conclusion}

Approximately half of the world's population prefers coal or biomass fuels such as wood, animal manure, or crop residues for their energy needs (WHO 2018). There is evidence that the transition from biomass to cleaner fuels in heating and cooking, especially in low-income groups, has decreased significantly over the years (Bruce et al. 2002). This in turn has caused increased indoor air pollution and health problems.

Although the health impacts of air pollution have been examined by many studies in Turkey, the number of studies on the health effects of indoor air pollution has been limited. In this paper, we determined the effects of indoor air pollution caused by households' energy choice on household health, applying random effects panel discrete ordered models on the Micro
Longitudinal Data Set in Turkey. In contrast to previous studies, we considered unobserved heterogeneity between the households. We found that age, gender, and having dependent children in the household negatively affect household health. However, income, education, and homeownership are positively affected. Education is an important variable that positively affects a person's health status. We also created the standard of living index using various indoor settings and economic variables. While the major determinants of the health-related indoor settings are toilets, kitchens, water systems, and hot water systems, the minor determinants are internet services, TVs, and computers. With the help of standard of living index, we found that higher standard of living of households have serious impact on their health. In addition, we noted that although a household's socioeconomic variables affect health, these effects are relatively limited. On the other hand, indoor air pollution is an important variable that affects the health status of individuals. Moreover, the impact of indoor air pollution on health is higher than that of income level.

These findings are significant because indoor air pollution, which is caused by reliance on biomass energy in heating and cooking, has serious effects on the health status of individuals living in a household. Therefore, determining this effect empirically will provide guidance for decision-makers in energy and environmental policies. As a result of the study, we can report that even if households have high-income levels, their inability to access clean energy resources has serious negative effects on health. Particularly in developing countries such as Turkey, economic development and increases in the national 
income are not adequate for increasing public health. In these countries, access to clean and safe energy sources should also be increased. For this reason, policymakers should focus on infrastructure services to increase households' access to clean and reliable energy sources.

Author contribution All authors contributed to the study conception and design. Material preparation, data collection, and analysis were performed by Özlem İpek and Egemen İpek. The first draft of the manuscript was written by Özlem İpek and all authors commented on previous versions of the manuscript. All authors read and approved the final manuscript and agree to be accountable for all aspects of the work.

Availability of data and materials The data supporting the findings of this study are available from the Turkish Statistical Institute. Restrictions apply to the availability of these data, which were used under license for this study.

\section{Declarations}

Ethics approval and consent to participate Not applicable

Consent for publication Not applicable

Competing interests The authors declare no competing interests.

\section{References}

Agrawal S (2012) Effect of indoor air pollution from biomass and solid fuel combustion on prevalence of self-reported asthma among adult men and women in India: findings from a nationwide large-scale cross-sectional survey. J Asthma 49(4):355-365. https://doi.org/10. 3109/02770903.2012.663030

Agrawal S, Yamamoto S (2015) Effect of indoor air pollution from biomass and solid fuel combustion on symptoms of preeclampsia/ eclampsia in Indian women. Indoor Air 25(3):341-352. https://doi. org/10.1111/ina.12144

Albalak R, Frisancho AR, Keeler GJ (1999) Domestic biomass fuel combustion and chronic bronchitis in two rural Bolivian villages. Thorax 54:1004-1008. https://doi.org/10.1136/thx.54.11.1004

Albalak R, Bruce N, McCracken JP, Smith KR, De Gallardo T (2001) Indoor respirable particulate matter concentrations from an open fire, improved cookstove, and LPG/open fire combination in a rural Guatemalan community. Environ Sci Technol 35(13):2650-2655. https://doi.org/10.1021/es001940m

Armstrong JR, Campbell H (1991) Indoor air pollution exposure and lower respiratory infections in young Gambian children. Int $\mathrm{J}$ Epidemiol 20:424-429. https://doi.org/10.1093/ije/20.2.424

Baltagi BH (2001) Econometric analysis of panel data, 2d edn. John Wiley \& Sons, New York

Barnes DF, Floor W (1999) Biomass energy and the poor in the developing world. J Int Aff 53(1):237-259. https://www.jstor.org/stable/ 24357794. Accessed 11 Jul 2021

Boy E, Bruce N, Delgado H (2002) Birth weight and exposure to kitchen wood smoke during pregnancy in rural Guatemala. Environ Health Perspect 110(1):109-114. https://doi.org/10.1289/ehp.02110109

Breysse PN, Diette GB, Matsui EC, Butz AM, Hansel NN, McCormack MC (2010) Indoor air pollution and asthma in children. Proc Am
Thorac Soc 7(2):102-106. https://doi.org/10.1513/pats.200908083RM

Bruce N, Perez-Padilla R, Albalak R (2000) Indoor air pollution in developing countries: a major environmental and public health challenge. Bull World Health Organ 78(9):1078-1092. Available via https://www.scielosp.org/pdf/bwho/2000.v78n9/1078-1092/en. Accessed 11 Jul 2021

Bruce N, Perez-Padilla R, Albalak R (2002) The health effects of indoor air pollution exposure in developing countries. World Health Organization, Geneva Available via http://stoves.bioenergylists. org/stovesdoc/Environment/WHO/OEH02.5.pdf

Bruce N, McCracken J, Albalak R, Scheid M, Smith KR, Lopez V, West C (2004) Impact of improved stoves, house construction and child location on levels of indoor air pollution exposure in young Guatemalan children. J Exp Sci Environ Epidemiol 14(1):S26S33. https://doi.org/10.1038/sj.jea.7500355

Cerqueiro MC, Murtagh P, Halac A, Avila M, Weissenbacher M (1990) Epidemiologic risk factors for children with acute lower respiratory tract infection in Buenos Aires, Argentina: a matched case-control study. Rev Infect Dis 12(8):S1021-S1028. https://doi.org/10.1093/ clinids/12.Supplement 8.S1021

Collings DA, Sithole SD, Martin KS (1990) Indoor woodsmoke pollution causing lower respiratory disease in children. Trop Dr 20:151-155. https://doi.org/10.1177/004947559002000403

Commodore AA, Hartinger SM, Lanata CF, Maeusezahl D, Gil A et al (2013) A pilot study characterizing real time exposures to particulate matter and carbon monoxide from cookstove related woodsmoke in rural Peru. Atmos Environ 79:380-384. https://doi.org/10.1016/j. atmosenv.2013.06.047

De Francisco A, Morris J, Hall AJ, Armstrong Schellenberg JR, Greenwood BM (1993) Risk factors for mortality from acute lower respiratory tract infections in young Gambian children. Int J Epidemiol 22:1174-1182. https://doi.org/10.1093/ije/22.6.1174

Demjén T, Buda B, Gallay L (2000) Project for public awareness of indoor exposure to tobacco smoke in Hungary. In: Lu R, Mackay J, Niu S, Peto R (eds) Tobacco: The Growing Epidemic. Springer, London. https://doi.org/10.1007/978-1-4471-0769-9 63

Dionisio KL, Howie S, Fornace KM, Chimah O, Adegbola RA, Ezzati M (2008) Measuring the exposure of infants and children to indoor air pollution from biomass fuels in The Gambia. Indoor Air 18:317327. https://doi.org/10.1111/j.1600-0668.2008.00533.x

Duflo E, Greenstone M, Hanna R (2008) Cooking stoves, indoor air pollution and respiratory health in rural Orissa. Econ Polit Wkly 43(32):71-76. Retrieved January 25, 2021, from http://www.jstor. org/stable/40277832. Accessed 11 Jul 2021

Dutt D, Srinivasa DK, Rotti SB, Sahai A, Konar D (1996) Effect of indoor air pollution on the respiratory system of women using different fuels for cooking in an urban slum of Pondicherry. Natl Med J India 9:113-117

Ezzati M (2005) Indoor air pollution and health in developing countries. Lancet 366(9480):104-106. https://doi.org/10.1016/S01406736(05)66845-6

Ezzati M, Kammen DM (2001) Indoor air pollution from biomass combustion and acute respiratory infections in Kenya: an exposureresponse study. Lancet 358:619-624. https://doi.org/10.1016/ S0140-6736(01)05777-4

Ezzati M, Kammen DM (2002) Household energy, indoor air pollution and health in developing countries: knowledge base for effective interventions. Annu Rev Energy Environ 27:233-270. https://doi. org/10.1146/annurev.energy.27.122001.083440

Fullerton DG, Bruce N, Gordon SB (2008) Indoor air pollution from biomass fuel smoke is a major health concern in the developing world. Trans R Soc Trop Med Hyg 102(9):843-851. https://doi. org/10.1016/j.trstmh.2008.05.028

Gao X, Yu Q, Gu Q, Chen Y, Ding K, Zhu J, Chen L (2009) Indoor air pollution from solid biomass fuels combustion in rural agricultural 
area of Tibet, China. Indoor Air 19(3):198-205. https://doi.org/10. 1111/j.1600-0668.2008.00579.x

Hoskins JA (2003) Health effects due to indoor air pollution. Indoor Built Environ 12(6):427-433. https://doi.org/10.1177/ 1420326X03037109

Income and Living Conditions Survey Micro Longitudinal Data Set (2017) Turkish Statistical Institute, Ankara

Institute of Medicine (2011) Climate change, the indoor environment, and health. The National Academies Press, Washington. https://doi.org/ $10.17226 / 13115$

Johnson AW, Aderele WI (1992) The association of household pollutants and socio-economic risk factors with the short-term outcome of acute lower respiratory infections in hospitalized pre-school Nigerian children. Ann Trop Paediatr 12:421-432. https://doi.org/ 10.1080/02724936.1992.11747609

Khalequzzaman M, Kamijima M, Sakai K, Chowdhury NA, Hamajima N, Nakajima T (2007) Indoor air pollution and its impact on children under five years old in Bangladesh. Indoor Air 17(4):297-304. https://doi.org/10.1111/j.1600-0668.2007.00477.x

Kim KH, Jahan SA, Kabir E (2011) A review of diseases associated with household air pollution due to the use of biomass fuels. J Hazard Mater 192(2):425-431. https://doi.org/10.1016/j.jhazmat.2011.05. 087

Kovesi T, Creery D, Gilbert NL, Dales R, Fugler D, Thompson B, Randhawa N, Miller JD (2006) Indoor air quality risk factors for severe lower respiratory tract infections in Inuit infants in Baffin Region, Nunavut: a pilot study. Indoor Air 16(4):266-275. https:// doi.org/10.1111/j.1600-0668.2006.00423.x

Lakshmi PV, Virdi NK, Sharma A, Tripathy JP, Smith KR, Bates MN et al (2013) Household air pollution and stillbirths in India: analysis of the DLHS-II National Survey. Environ Res 121:17-22. https:// doi.org/10.1016/j.envres.2012.12.004

Long JS, Freese J (2014) Regression models for categorical dependent variables using stata, 3rd edn. Stata Press, College Station

Mishra VK (2003) Indoor air pollution from biomass combustion and acute respiratory illness in preschool age children in Zimbabwe. Int J Epidemiol 32(5):847-853. https://doi.org/10.1093/ije/dyg240

Mishra VK, Retherford RD, Smith KR (1999) Biomass cooking fuels and prevalence of tuberculosis in India. Int J Infect Dis 3(3):119-129. https://doi.org/10.1016/S1201-9712(99)90032-2

Mishra VK, Dai X, Smith KR, Mika L (2004) Maternal exposure to biomass smoke and reduced birth weight in Zimbabwe. Ann Epidemiol 14:740-747. https://doi.org/10.1016/j.annepidem.2004. 01.009

Morris K, Morgenlander M, Coulehan JL, Gahagen S, Arena VC, Morganlander M (1990) Wood-burning stoves and lower respiratory tract infection in American Indian children. Am J Dis Child 144(1): 105-108. https://doi.org/10.1001/archpedi.1990.02150250117047

OECD (2021) Glossary of statistical terms. https://stats.oecd.org/ glossary/detail.asp?ID=1336. Accessed $11 \mathrm{Jul} 2021$

Pearce D (1996) Economic valuation and health damage from air pollution in the developing world. Energy Policy 24:627-630. https://doi. org/10.1016/0301-4215(96)00051-1
Pérez-Padilla R, Schilmann A, Riojas-Rodriguez H (2010) Respiratory health effects of indoor air pollution. Int J Tuber Lung Disease 14(9):1079-1086. https://pubmed.ncbi.nlm.nih.gov/20819250. Accessed 11 Jul 2021

Qiu Y, Yang FA, Lai W (2019) The impact of indoor air pollution on health outcomes and cognitive abilities: empirical evidence from China. Popul Environ 40:388-410. https://doi.org/10.1007/ s11111-019-00317-6

Saha A, Kulkarni PK, Shah A, Patel M, Saiyed HN (2005) Ocular morbidity and fuel use: an experience from India. Occup Environ Med 62(1):66-69. https://doi.org/10.1136/oem.2004.015636

Salvi S, Barnes PJ (2010) Is exposure to biomass smoke the biggest risk factor for COPD globally? Chest 138(1):3-6. https://doi.org/10. 1378/chest. 10-0645

Schei MA, Hessen JO, McCraken J, Lopez V, Bruce N, Smith KR (2002) Asthma and indoor air pollution among indigenous children in Guatemala. Paper presented at the 9th International Conference on Indoor Air Quality and Climate, Monterey

Shah N, Ramankutty V, Premila PG, Sathy N (1994) Risk factors for severe pneumonia in children in south Kerala: a hospital-based case-control study. J Trop Pediatr 40(4):201-206. https://doi.org/ 10.1093/tropej/40.4.201

Shrestha IL, Shrestha SL (2005) Indoor air pollution from biomass fuels and respiratory health of the exposed population in Nepalese households. Int J Occup Environ Health 11(2):150-160. https://doi.org/ 10.1179/oeh.2005.11.2.150

Smith KR (1987) Biofuels, air pollution, and health: a global review. Plenum, New York

Smith KR (1993) Fuel combustion, air pollution exposure, and health: the situation in developing countries. Ann Rev Environ Energy 18:529 566. https://doi.org/10.1146/annurev.eg.18.110193.002525

Smith KR, Samet JM, Romieu I, Bruce N (2000) Indoor air pollution in developing countries and acute lower respiratory infections in children. Thorax 55(6):518-532. https://doi.org/10.1136/thorax.55.6. 518

Sofoluwe GO (1968) Smoke pollution in dwellings of infants with bronchopneumonia. Arch Environ Health 16(5):670-672. https://doi. org/10.1080/00039896.1968.10665126

Subramanian J, Govindan R (2007) Lung cancer in never smokers: a review. J Clin Oncol 25(5):561-570. https://doi.org/10.1200/JCO. 2006.06.8015

Wooldridge JM (2002) Econometric analysis of cross section and panel data. MIT Press, Cambridge

Wooldridge JM (2020) Introductory econometrics: a modern approach, 7 th edn. Cengage, Boston

World Health Organization (WHO) (2018). Household air pollution and health. Available via: http://www.who.int/en/news-room/factsheets/detail/household-air-pollution-and-health. Accessed 11 Jul 2021

Publisher's note Springer Nature remains neutral with regard to jurisdictional claims in published maps and institutional affiliations. 